DOI: 10.20472/IAC.2018.001.028

\author{
BENJAWAN YOTRAWAT \\ Suan Sunandha Rajabhat University, Thailand
}

ASSISTANT PROFESSOR DR. SOMDECH RUNGSRISAWAT

Suan Sunandha Rajabhat University, Thailand

\title{
SUSTAINABLE SERVICE QUALITY TO MEET WITH CUSTOMER EXPECTATION
}

\begin{abstract}
:
One of the strengths of Thai tourism is the high standard of service quality of Thai hotels. Therefore, it is vital for Thai hotel industry to maintain and ameliorate the service quality in a sustainable way. The question is whether the high standard of service quality meets with customers' expectation or not. The purposes of this research were to examine the level of satisfaction in ten areas of services from the perspectives of international tourists whether their expectations of the service quality have been met or not. The population of study included all international tourists who visited Thailand the first quarter of year 2018. A total of 400 samples was interviewed with English questionnaire. The findings revealed that in general the respondents had a very high expectation of service quality and the majority of their expectations in ten areas of services had been fulfilled. There were two areas of service quality that needed to be improve which were transportation services and ability to communicate in other languages such as Russia, Arabic, and Chinese.
\end{abstract}

\section{Keywords:}

Service Quality, Customer Expectation, International Tourists

JEL Classification: Y80 


\section{Background}

It is an acceptable fact that tourism and hotel business environment both domestic and international level is becoming highly competitive and challenging now more than the past two or three decades. Many small nations or small economies which depend so much on tourist revenue need to make sure that their tourism resources are competitive in the modern globalization in which information about tourism destinations and its standard of quality are reported on social media as quickly as possible. Both good news and bad news of tourism and hotel industry spread into all over the world virally due to the power of modern information technology and impacts of social media. The research of service quality is important for both hotel business and tourism business to evaluate themselves and its competitors to be able to compete in the long term business. Intensified competition is not a bad thing, in fact, it forces the industry and business to be more attentive to enhance their standard of service quality to make sure customers are satisfied with the highest level (Li \& Lu, 2010). The majority of the research paper in the past often focus on collecting the data to prove the level of satisfaction of customers.

Regardless of the size of the hotel business and whether it is located in anyplace in Thailand, to be successful depends on a high level of sustainable service quality to enhance customer's level of satisfaction (Morgan, Anderson, and Mittal, 2005). Since it is widely accepted that customer satisfaction strategies, it should be an important focus on hotel and tourism industry of Thailand as well as to be a major competitive advantage. In fact, customer satisfaction arises when the organization or service providers can provide customers with benefits or value added that equal to or ex exceed customers' expectation. In general, if customers are satisfied with product or services, they have a tendency to buy more, to repurchase, and to recommend others to buy (Gutierrez \& Uribe, 2011). Therefore, it is imperative for hotel and tourism business and industry always to make certain that customers happy by exceeding their expectations in order to win their loyalty in the long run.

In fact, there are many different factors affecting customers' satisfaction, however, the service quality is considered to one of the most important factors affecting customers' satisfaction level. Many of hotel and tourism research have agreed that service quality is a vital factor and have a positive direct relationship with customers' satisfaction. And the SERVQUAL instrument (Zeithaml, Parasuraman, and Berry, 1985, 1990) has been acclaimed and considered as the most important and effective tools used to assess service quality as well as to measure the service quality to offer any suggestion to be improved in the areas of service quality (Andaleeb \& Conway (2006). 


\section{Literature Review}

The main focus of measurement of service quality is to understand the tool called SERVQUAL (Zeithaml, Parasuraman, and Berry, 2006) which included five dimensions. First is reliability which is ability to perform the service with accuracy and dependable manner. Second is assurance is about the knowledge and courtesy of staff or employees with their ability to convey trust and confidence. Third is tangibles which means the appearance of physical factors such as equipment, rooms, facilities, atmosphere, and personal. Fourth is empathy which is how to provide individual attention and individual detail care to customer. Finally, the last one is responsiveness which refers to the willingness to provide help and prompt service to customers.

Customer satisfaction is widely accepted as a measurement of how a product or services from the organizations to fail to meet, or to meet or to exceed customers' expectation. If the product or service fails to meet customers' expectation, customers will surely have a low level of satisfaction. If the product or services meet with customers' expectation, customers will surely have a medium to high level of satisfaction. However, it the product or service exceed customers' expectation, customer will certainly have a high level of satisfaction and behave positively to the product, service, or even the organization that provides the product or service. Customer satisfaction is often considered as a key performance indicator within business and implies how the organization is successful or not in the market. In the modern globalization, customers' satisfaction is a competitive advantages that all firms need to acquire. In fact, it is impossible for any business or any organization to sustain in the long term without customer satisfaction. This is because customer satisfaction often leads to customer retentions and customer loyalty. Therefore, customer satisfaction is the first gate that leads to customer retention, customer loyalty, and long run profit and long run success of the organization. In any competitive market, firms compete each other to gain more customer or in other words, to gain more market share (Torres and Kline, 2013). However, it is impossible to gain and maintain market share in the long run without the success of customers' satisfaction.

Customers' expectation of service quality depends on the how much and how long the product of service meet with customer expectation. The gap of the expectation and real experience implies the areas of customers' satisfaction. High gap means low level of satisfaction and low gap means high level of satisfaction. To ensure high service quality to reduce the gap of expectation and real experience of customers. The service providers need to do a good job in the areas of reliability, assurance, tangibility, empathy, and responsiveness (Wongleedee, 2013). 


\section{Methods}

The purposes of this research were to examine the level of satisfaction in ten areas of services from the perspectives of international tourists whether their expectations of the service quality have been met or not. The ten areas of services in the typical hotel included doorman, front office, lobby areas, housekeeping, room service, restaurant, restroom, computer room, pool, and fitness. These ten areas are where the customers need the services at all times and often experience good or bad service quality at these ten important areas. The population of study included all international tourists who visited Thailand the first quarter of year 2018. A special English questionnaire is designed and developed specifically for the purpose of data collection of this research. A total of 400 samples was interviewed by using English questionnaire. In order to reduce the gender effect, the researcher divided the sample into two groups of male and female customers equally. In other words, for data collection, male and female customers have been collected in the same proportion, or 50:50 respectively.

The content of validity of the interview questions was tested by using three experts who had a long experience in hotel and tourism business and industry to read and approve the questionnaire by all three experts. The content of reliability of interview questions was tested by using the pilot study of 30 target samples and utilizing Cronbach's Alpha Coefficient. All the question is expected to pass at least 0.75 of Cronbach's Alpha coefficient. Statistical analysis was performed by using percentage, mean and standard deviation. There are two tables to explain the ten areas of services that international customers that meet or exceed customers' expectation and the second table is about the level of satisfaction of five dimensions of services.

\section{Findings}

The findings of this research study revealed that, in order to reduce the gender effects, male and female customers have been collected in the same proportion, or 50:50 respectively. The majority had at least one visit with Thai hotel. The majority of respondents were interested in providing information and willing to provide comments on five dimension of services. From table 1, it shows that in ten services areas that meet or exceed customer expectation. There are four areas that have higher percentage of meeting or exceeding customer expectation which are restaurants, front office, doorman, and housekeeping. From table 2, which shows five dimensions of services of male and female customers. It is obvious that female rated all five dimension of services with less satisfaction than male customers and both had rated the overall five dimension of services with a medium level of satisfaction. The overall means for male customers is 3.36 whereas the female 
customers is only 3.09. In other word, it implies that customers have a very high expectation of service quality. Even though the Thai hotels have a very high standard of service quality in general, but international customers seem to have a very high expectation of service quality. Therefore, the customers may rate with their real experiences that many service quality are good but not good enough by their high standard of service quality.

Table 1. Ten Service Areas that Meet or Exceed Expectation

\begin{tabular}{lc}
\hline \multicolumn{1}{c}{$\begin{array}{c}\text { Services Meet or } \\
\text { Exceed } \\
\text { Expectation: }\end{array}$} & Percentage (\%) \\
\hline 1. Doorman & 12 \\
2. Front office & 24 \\
3. Lobby areas & 4 \\
4. Housekeeping & 12 \\
5. Room service & 11 \\
6. Restaurants & 30 \\
7. Restrooms & 3 \\
8. Computer room & 7 \\
9. Pool & 5 \\
10. Fitness & 3 \\
Total & 100 \\
\hline \hline
\end{tabular}

Table 2. Five Dimensions of Services

\begin{tabular}{lcc}
\hline $\begin{array}{c}\text { Five dimensions of } \\
\text { Services }\end{array}$ & $\begin{array}{c}\text { Male } \\
\text { customers }\end{array}$ & $\begin{array}{c}\text { Female } \\
\text { Customers }\end{array}$ \\
\hline 1. Reliability & 2.98 & 2.71 \\
2. Assurance & 3.98 & 3.45 \\
3. Tangibles & 3.51 & 3.48 \\
4. Empathy & 3.69 & 3.34 \\
5. Responsiveness & 2.68 & 2.50 \\
\multicolumn{1}{c}{ overall } & 3.36 & 3.09 \\
\hline \hline
\end{tabular}




\section{Suggestions}

From the conducting of this research, it found that service quality may be more difficult for customers to evaluate than product quality. Therefore, it needs both quantitative and qualitative research technique to search for the correct and quantifiable answers to the research questions. Second, services quality perceptions result from the comparison between expectation and actual real experience of service performance. It may be the case that customers have a very high expectation that is very hard to reach especially during the perk seasons or peak demand of the hotels in Thailand. Third, it should be noted that quality evaluation should not be made solely by the interview since they are many forms of services and a variety of measurement.

\section{Future Studies}

The limitation of this research paper occurs mainly because the sample group which included only international customers in Bangkok. It should include other international customers in other tourist destinations such as Pattaya, Phuket, Hua-Hin. Hence, the findings may not be generalized to find the proper picture of service quality. Therefore, future research should use a proportion sampling technique with a diverse group of international customers. Moreover, future studies should use more in-depth interviews to find the reasons behind their comment on service quality.

\section{Acknowledgement and Legal Responsibility}

I would like to thank the Graduate School, and Institution of Research and Development, Suan Sunandha Rajabhat University for their kind support. The big thanks also go to the respondents of this survey for kind sharing of information of their knowledge, experience, and comments. Also, my appreciation goes to Asst. Prof. Dr. Kevin Wongleedee, Director of Institute of Lifelong Learning Promotion and Creativity for his proof reading of this manuscript. 


\section{References}

Andaleeb, S. and Conway, C. (2006). Customer satisfaction in the restaurant industry: an examination of the transaction specific model. Journal of Services Marketing, 20(1), pp.3-11.

Dominici, G. and Guzzo, R. (2010). Customer Satisfaction in the Hotel Industry: A Case Study from Sicily. IJMS, 2(2).

G/Egziabher, A. (2015). Service Quality and Customer Satisfaction in Hotel Industry: The Case of Three Star Hotels in Addis Ababa, Ethiopia. Post Graduate. Addis Ababa University.

Gutierrez, S. and Uribe, G. (2011). Customer satisfaction in the hospitality industry in Guadalajara, Mexico. Advances in Competitiveness Research, 19(4), pp.17-30.

Li, W. and Lu, Y. (2010). How Service Climate Impacts on Service Performance: Evidence from China Hotel Industry. 2010 International Conference on Management and Service Science.

Morgan, N., Anderson, E. and Mittal, V. (2005). Understanding Firms' Customer Satisfaction Information Usage. Journal of Marketing, 69(3), pp.131-151.

Seo, Y. (2012). Cultural Impact on Customer Satisfaction and Service Quality Evaluation in Hotels. Postgraduate. University of Nevada, Las Vegas.

Torres, E. and Kline, S. (2013). From customer satisfaction to customer delight. International Journal of Contemporary Hospitality Management, 25(5), pp.642-659.

Wongleedee, K. 'International Tourists' motivation to revisit Bangkok, Thailand. Proceeding from WASET Conference, Paris, 2014. International College, Suan Sunandha Rajabhat University. 2014.

Zeithaml, Bitner, M., Gremler, D. and A, V. (2006). Services Marketing: Integrating Customer Focus across the Firm. 4th ed. Singapore: McGraw-Hill, pp.117, 119.

Zeithaml, V., Parasuraman, A. and Berry, L. (1990). Delivering quality service. New York: Free Press. 